ships were conferred on nine professors of not less than five years standing at the College, and the fellowship was conferred on Atholl Blair and $H$. Shoosmith. A Finsbury Medal has been instituted at the instance of the Finsbury Technical College Old Students' Association, and this body, in terminating the Streatfeild Memorial Lectures, has also offered the balance of the Fund to establish a major annual prize in a suitable branch of chemical technology, if possible where emphasis can be placed upon practical work. The first new Insignia awards (see Nature, 170,$828 ; 1952$ ) were expected to be made during the winter of 1952 , and the Institute believes that the introduction of the award will encourage students to take full advantage of the facilities provided in industry and technical colleges and lead to recognition of the value of practical training and experience. A deficit of $£ 6,278$ on the year and depreciation of the Institute's investments threaten curtailment of activities unless new income can be found.

\section{Jubilee of the School Nature Study Union}

THE latest issue of the School Nature Study Union journal (School Nature Study) represents a memorable event in the life of the organization-its fiftieth birthday. The Union was founded in 1903, largely owing to the enthusiasm of the Rev. Claude Hinscliff and Miss Kate Hall, and soon became the means of promoting considerable interest in the study of natural history in schools. The first president was Sir George Kekewich, and the vice-presidents included Lord Beauchamp, Sir John Cockburn, Sir Lauder Brunton, Mrs. Humphrey Ward and, later, Mr. H. G. Wells. During its life, many eminent biologists have served the Union as presidents or in other capacities, although probably no names are more pre-eminent than those of Miss C. Von Wyss and Mr. H. E. Turner, who were both members of the original committee formed in 1905 until their resignation in 1936. Besides the journal, which has been appearing for forty-eight years, the School Nature Study Union has performed a most useful service to teachers and others in the production of an extensive series of leaflets which give practical advice on how to teach natural history more effectively. Cordial greetings are extended to the School Nature Study Union in its jubilee year.

\section{Botanical Gallery at Bolton}

ThOUGH the Museum and Art Gallery at Bolton was built just before the War it was only possible recently to install a botanical gallery. This is recently to in the Museums Journal for May by Mr. A. Hazelwood and indicates clearly some of the aspects of botany which can be so illustrated. Naturally recourse to modelling was considered essential, and the first exhibit is an enlarged model of a poppy which is used for demonstrating terms of a poppy the various parts of a flowering plant. applied to the various parth the morphology and some aspects of the physiology of the flowering plant, root aspects of the phys, nutrition and adaptation to specialized environments, together with the fruit, dispersal and germination of a variety of plants. Another section is systematic and, after a series of Another section is sol of microscopic forms, follows colour transparencies of mith models of the larger thallophytes to the Angiosperms. Emphasis is given to the illustration of sperms. Emphasis is geries concludes with exhibits showing plants as food.

\section{Herbarium of Indian Plants}

THE discovery of an important herbarium in a recent acquisition by the Liverpool Public Museums is related by Mr. H. Stansfield, keeper of the Department of Botany, in the March number of the Museums Journal. This collection, which was given by the Liverpool Chemists' Association, consisted of several thousand specimens with no data, and by patient investigation Mr. Stansfield has been able to record its history. By noting various clues and following several lines of investigation, he was able to prove that the plants were those on which the text and illustrations of J. F. Royle's "Illustrations of the Botany of the Himalayan Mountains and the Flora of Cashmere" were founded. Some of the plants were collected in the plains of India of the north-west provinces, some are from the mountainous tract between the Sutlej and the Ganges and others from the valleys of Kashmir (Cashmere). The plants from the last-named locality were obtained during 1828-31 by native collectors. The herbarium with its important type-specimens has been placed in good order and will no doubt be consulted by many workers.

\section{Feeding Mechanisms in Deep-Sea Fish}

Much of our knowledge of the habits and functioning of deep-sea fishes must, perforce, be derived from indirect evidence. From dissections of preserved material, the late Dr. V. V. Tchernavin has carefully reconstructed the probable sequence of movements involved in feeding in a bathypelagic stomiatoid teleost Chauliodus. His conclusions have now been published by the British Museum (Natural History) in a volume entitled "The Feeding Mechanisms of a Deep-Sea Fish Chauliodus sloani Schneider" (pp. viii $+101+10$ plates; $1953 ; 30 s$.). Jaw and head movements, basically similar to those of other teleosts, but on a much exaggerated scale, enable Chauliodus to capture and ingest prey larger than itself. For comparison with Chauliodus, the feeding mechanisms of certain other vertebrates are described briefly. Other valuable details described in the volume are the operation of breathing valves, the distribution and possible significance of light. organs in Chauliodus, and the dissimilar feeding mechanism of another bathypelagic teleost, Saccopharynx (order Lyomeri). There is an extensive bibliography.

\section{Linen Research Association: Report for 1952}

THE report of the council of the Linen Research Association for the year ended September 30, 1952 (pp. 24; from the Association, Lambeg, Northern Ireland; 1952), records steady progress in almost every section of the Association's activities. Research on flax production has again been a matter of concern to the industry, and the council records its thanks to the Flax Development Committee for continued support of its research on flax scutch. The flax-production seheme in England is now to continue on a permanent basis, and also research work in Norfolk, but on a reduced scale. In the work on rayon staple, various causes of shading faults in plain dyed fabrics have been revealed and recommendations made for reducing the faults to a minimum. Arrangements have been made for the manufacture of the Linra photo-electric yarn irregularity gauge to assist in keeping yarn irregularity below a fixed level, and comparative tests of the Linra modified roller-breaker 